\title{
LA TENTACIÓN DE LO SERIO: A PROPÓSITO DE EL ASTRÓLOGO FINGIDO
}

\author{
Fernando Rodríguez-Gallego \\ Universitat de les Illes Balears \\ Dpt. de Filologia Espanyola, Moderna i Clàssica \\ Edifici Ramon Llull \\ Cra.Valldemossa Km. 7,5 \\ 07122 Palma de Mallorca \\ España \\ f.rodriguez-gallego@uib.cat
}

Al menos durante los últimos doscientos años, Calderón de la Barca ha sido visto principalmente como un autor serio. Desde finales del siglo XVIII y, en particular, desde inicios del xIx, Calderón se convirtió en el dramaturgo que mejor representaba una manera de entender España, en el dramaturgo del honor, del catolicismo y de la monarquía, y fue elevado a la condición de icono cultural e identitario del conservadurismo español, según ha estudiado Jesús Pérez-Magallón en un reciente libro ${ }^{1}$. Entre otras consecuencias, el triunfo de este Calderón serio conllevó la progresiva relegación de su teatro cómico, con la única excepción de La dama duende.

Hubo que esperar a la segunda mitad del siglo xx para que las comedias cómicas de nuestro autor empezasen a ser reconsideradas por los estudiosos, aunque para ello se eligió el camino de equipararlas con las obras propias del Calderón más reconocido: es decir, se les buscó un significado o un mensaje serios, si no trágicos; se atenuaba la distancia entre El médico de su honra y La dama duende, entre La vida es sueño y El mayor encanto, amor. En el fondo, todas ellas venían a decir lo mismo y

\footnotetext{
${ }^{1}$ Pérez-Magallón, 2010.
} 
tenían un fundamento sobre todo serio; su mensaje último era siempre serio, y los ropajes en apariencia cómicos eran solo aditamentos que el buen crítico sabía apartar para extraer al Calderón más puro. Lo que en la superficie parece una comedia de capa y espada es realmente una tragedia; lo que en la superficie parece una fiesta cortesana es en realidad una severa crítica política².

Es interesante destacar que esta imagen de un Calderón serio que ha predominado en al menos los últimos dos siglos parece chocar con la que debían de tener los contemporáneos de don Pedro. Así, gracias a importantes proyectos de investigación como DICAT o CATCOM ${ }^{3}$ podemos aproximarnos a las obras de Calderón que predominaban en las tablas en el siglo XVII. Y comparar las piezas más representadas en aquel siglo, de acuerdo con los datos siempre parciales que proporcionan los mencionados proyectos, con las de más éxito durante cincuenta años del siglo xx (1939-1989), es lo que ha hecho Purificació Mascarell en un reciente artículo. De acuerdo con los datos que proporciona Mascarell, las siete obras de Calderón más representadas durante esos cincuenta años del siglo xx son"

$\begin{array}{ll}\text { La vida es sueño } & 30 \\ \text { El alcalde de Zalamea } & 27 \\ \text { El gran teatro del mundo } & 14 \\ \text { La dama duende } & 13 \\ \text { La cena del rey Baltasar } & 8 \\ \text { La hidalga del valle } & 6 \\ \text { El pleito matrimonial del cuerpo y el alma } & 5\end{array}$

El predominio del Calderón serio es evidente, pues solo se cuela en este canon una comedia cómica, La dama duende, y habría que alargar mucho la lista para volver a encontrar otra. Aunque también es cierto que esa amplia presencia de autos sacramentales, con nada menos que cuatro, sería probablemente más reducida si la horquilla de fechas se

\footnotetext{
${ }^{2}$ Sobre las lecturas tragedizantes de comedias cómicas se tratará más adelante; sobre el debate en torno a la interpretación política de las fiestas mitológicas de Calderón pueden verse, a modo de ejemplo, Fernández Mosquera, 2015a, y De Armas, 2011, donde encontrará el lector interesado más bibliografía.

${ }^{3}$ Ver Ferrer, 2008, y <http://catcom.uv.es/> [01/10/2016].

${ }^{4}$ Mascarell, 2013, p. 306.
} 
hubiese alejado del franquismo y se hubiese acercado más al momento presente ${ }^{5}$.

En todo caso, la lista contrasta de modo llamativo con la de las siete obras de Calderón más representadas en el siglo XVII, de acuerdo con los datos del CATCOM, que son las siguientes ${ }^{6}$ :

Afectos de odio y amor

También hay duelo en las damas

Agradecer y no amar

El secreto a voces

Dicha y desdicha del nombre

La dama duende

Antes que todo es mi dama

Como puede apreciarse, las siete obras son cómicas, y de ahí que solo haya una coincidencia entre ambas listas: La dama duende. Este elenco evidencia, además, la desatención actual al Calderón cómico: como indica Mascarell ${ }^{7}$, ninguna de las tres comedias con más representaciones documentadas en el XVII parece haber sido puesta en escena nunca en el siglo xx, como tampoco Dicha $y$ desdicha del nombre, la situada en quinto lugar, al tiempo que las puestas en escena de El secreto a voces y Antes que todo es mi dama fueron mínimas. Y es más: también podemos observar que, de estas siete comedias, solo una es editada con cierta frecuencia, $\mathrm{La}$ dama duende, mientras que otras dos, Antes que todo es mi dama y El secreto a voces, solo han hallado acomodo, en los últimos años, en la excelente colección de ediciones críticas de la editorial Reichenberger, destinada primordialmente a un público de especialistas. De las otras cuatro, cuatro de las siete comedias de Calderón más representadas en el siglo XVII, no

${ }^{5}$ En efecto, en los últimos años parece haberse equilibrado en parte la situación, aunque todavía predomina el Calderón más serio. Así, la propia Mascarell señala, tratando de los montajes de la Compañía Nacional de Teatro Clásico (1986-2011), que «en ocho ocasiones se han visto dramas o tragedias calderonianas, mientras que su vertiente cómica ha contado con seis muestras en escena», de tal modo que la CNTC «mantiene la tendencia tradicional que asimila a Lope con los ligeros enredos amorosos y a Calderón con los elevados y rigurosos conceptos» (2014, p. 521). Puede verse también Adillo Rufo, 2013, y su tesis aún en curso. Agradezco a Sergio Adillo el haberme enviado estos materiales antes de su publicación.

${ }^{6}$ Mascarell, 2013, p. 308.

${ }^{7}$ Mascarell, 2013, pp. 308-309. 
contamos con edición crítica o exenta alguna y con apenas estudios, por lo que deben ser leídas en colecciones de obras completas de su autor.

Como es obvio, estos datos han de ser tomados con prudencia. La documentación conservada se refiere mayoritariamente a representaciones en palacio, y los autos sacramentales solo tendían a escenificarse durante el Corpus, para el que normalmente se escribían textos nuevos de año en año, lo que dificultaba que un mismo auto acumulase abundantes escenificaciones. Sin embargo, y a pesar de todas las matizaciones que quepa hacer, la tendencia parece clara, pues diferentes obras cómicas de Calderón que no han sido escenificadas nunca (insisto, nunca) o casi nunca en los últimos 130 años, sí han dejado noticias de representaciones en el siglo XVII relativamente abundantes, aunque estas puedan ser matizadas atendiendo al lugar de la representación o limitando más el arco cronológico. Pero el hecho es que esas representaciones existieron.

Si nos aproximamos al siglo XVIII, la situación con respecto a Calderón parece mantenerse. Así, de acuerdo con Paul Mérimée ${ }^{8}$, las comedias más representadas de aquel en las primeras décadas del XviII, hasta 1740, fueron: Mejor está que estaba, Para vencer a amor querer vencerle, Los empeños de un acaso, Cada uno para sí, Dar tiempo al tiempo, Antes que todo es mi dama, No siempre lo peor es cierto y El secreto a voces. De nuevo son todas comedias cómicas, de capa y espada o palatinas.

Este predominio cómico se aprecia también en los datos analizados por Germán Vega con respecto a Valladolid, que se adentran ya más en el siglo XVIII, pues estudia el período 1681-1766 ${ }^{9}$. Como comedia de Calderón más representada en esos años repite Afectos de odio y amor, aunque acompañada por Las armas de la hermosura, ambas con 23 representaciones. Un poco más abajo repite asimismo También hay duelo en las damas, con 14 representaciones, aunque asoma el Calderón que se irá convirtiendo en canónico, el de La vida es sueño y El alcalde de Zalamea (ambas con 13 representaciones).Vega analiza en su artículo cómo paulatinamente se van imponiendo nuevos autores sobre los barrocos, así como el nuevo gusto «por el "aparato" de las comedias de magia y, sobre todo, religiosas» ${ }^{10}$. Sin embargo, me interesa destacar uno de los mecanismos de supervivencia de los autores barrocos que trata Vega:

\footnotetext{
${ }^{8}$ Mérimée, 1975 , p. 133 , n. 40.

9 Vega García-Luengos, 1990.

${ }^{10}$ Vega García-Luengos, 1990, p. 660.
} 
La dimensión ceremonial del teatro deja su marca indeleble en otros aspectos más allá de la tendencia a la esclerotización de los repertorios. Es de resaltar, por ejemplo, la propensión a poner en escena determinadas comedias en la sesión inaugural de cada temporada, independientemente de la compañía que la emprenda.

Ahí están las seis ocasiones en que lo hace También hay duelo en las damas (1737, 1742, 1749, 1750, 1751 y 1756), o las siete de Afectos de odio y amor (1701, 1703, 1708, 1727, 1730, 1731 y 1745), ambas de Calderón ${ }^{11}$.

Es decir, de nuevo dos títulos cómicos de Calderón que han sido por completo olvidados, los mismos que predominaban en las tablas del XVII, adquieren un lugar prominente en la escena vallisoletana de la primera mitad del XviII, algo que sería impensable en al menos los últimos cien años.

Así, de acuerdo con estos datos, da la impresión de que, de igual modo que cuando a un lector o aficionado al teatro no especialista se le menciona hoy en día a Calderón, la primera imagen que se le venga a la cabeza será probablemente la de un autor serio, trágico, religioso, probablemente para un aficionado del XVII o del XVIII la primera impresión sería justamente la contraria, e ir a ver la última comedia de Calderón sería recibido con la expectativa de pasar unas horas de enredo, risa y diversión. El propio poeta parece insistir en esta perspectiva en sus guiños metateatrales, como cuando en No hay burlas con el amor dice don Alonso:

\author{
¿Es comedia de don Pedro \\ Calderón, donde ha de haber \\ por fuerza amante escondido \\ o rebozada mujer? ${ }^{32}$
}

Mientras que en La desdicha de la voz exclama Isabel:

${ }^{11}$ Vega García-Luengos, 1990,pp. 660-661. Este carácter predominante de Calderón en la inauguración de cada temporada también lo menciona, con respecto a Madrid, Sergio Adillo, quien destaca «El predominio de la comedia de enredo [de Calderón] para la inauguración de la temporada» (tesis doctoral en curso, cap. I). Adillo insiste en cómo poblaban los tablados dieciochescos comedias cómicas de Calderón que «desde entonces no han vuelto a pisar los escenarios».

${ }^{12}$ Calderón de la Barca, Comedias, V, p. 969. 
Que debe de ser comedia

sin duda esta de don Pedro

Calderón, que hermano o padre

siempre vienen a mal tiempo,

y ahora vienen ambos juntos (vv. 2225-2229)

Así, «ser comedia de don Pedro Calderón» vendría a entenderse como sinónimo de enredos eficaces, y de ahí lo chistoso del guiño.

En esta línea parecen abundar algunas menciones de Calderón en el Teatro de los teatros de Bances Candamo, uno de los primeros pilares en el proceso de canonización de Calderón. En efecto, parte de los elogios de Bances hacia nuestro dramaturgo se centran en su arte con respecto a las comedias de capa y espada.Y, aunque Bances las consideraba ya como algo pasado, sí insiste en que solo Calderón supo estrechar los lances de estas comedias «de modo que tuviesen viveza y gracia, suspensión en enlazarlos y travesura gustosa en deshacerlos» ${ }^{13}$.

Todavía en el siglo XVIII, en medio de las polémicas en torno al teatro barroco en las que se vieron envueltos los tradicionalistas y los neoclásicos, la imagen de Calderón que solían aducir estos últimos para criticarlo tendía a corresponderse con el de sus obras cómicas, percibidas como inmorales. Así se aprecia, por ejemplo, en el siguiente texto de una carta de Leandro Fernández de Moratín a Manuel Godoy de 1792:

El honor se funda en opiniones caballerescas y absurdas, que en vano han querido sofocar y extinguir las leyes, mientras el teatro las autoriza. No es caballero el que no se ocupa en amores indecentes, rompiendo puertas, escalando ventanas y ocultándose en los rincones, seduciendo criados, profanando, en fin, lo más sagrado del honor y atropellando aquellos respetos que deben contener las pasiones más violentas de todo hombre de bien. No es caballero tampoco el que no fía su razón a la espada, el que no admite y provoca el desafio por motivos ridículos y despreciables, el que no defiende el paso de una calle o de una puerta a la justicia, haciendo resistencia contra ella, matando e hiriendo a cuantos le amenazan con el nombre del rey y abriéndose paso a la fuga, que siempre se verifica, sin que estos delitos se vean castigados, como era consiguiente, sino antes bien aplaudidos con el nombre de heroicidad y de valor ${ }^{14}$.

${ }^{13}$ Bances Candamo, Theatro de los theatros, primera versión, p. 33.

${ }^{14}$ Citado en Pérez-Magallón, 2010, pp. 164-165. 
Pero Calderón también tuvo sus defensores en el xviII. Uno de ellos, Tomás de Erauso y Zabaleta (pseudónimo de Ignacio de Loyola Oyanguren), publica en 1750 su Discurso crítico sobre el origen... de las comedias en España, en el que defiende que el teatro al modo lopesco es el auténticamente nacional. Para Erauso, el referente icónico central será Calderón, pues él fue «el felicísimo autor de la primera más alta nobleza, decente y justificada del teatro español; y quien con la respetable nueva seriedad de su dulce delicado ingenio redimió enteramente la cómica de aquella escandalosa opinión que la conceptuaba ofensiva» ${ }^{15}$, en alusión a Lope. La nobleza propia de los españoles estará así bien reflejada en el teatro de don Pedro, pero en esta imagen ideal sobra el aspecto cómico: de Calderón se destaca su respetable nueva seriedad.

Esta marginación del Calderón más cómico parece asentarse a inicios del siglo XIX, con la querella calderoniana, cuando Calderón es reivindicado por Böhl de Faber como autor católico, como autor serio, cuya obra refleja unos valores consustanciales al carácter nacional español, visión que iría calando en las décadas siguientes.

Obviamente, el tema de la recepción de Calderón es muy complejo y no es mi propósito detenerme en ella ${ }^{16}$, pero sí me interesa destacar ahora que la paulatina conversión de Calderón en un autor conservador, católico y monárquico, identificado con una determinada manera de entender España, imagen que se extendió tanto entre los intelectuales conservadores, para apropiárselo, como entre los de espectro más liberal, para ir poco a poco rechazándolo, conllevó también la progresiva marginación del Calderón más lúdico y cómico ${ }^{17}$. Las comedias más divertidas y en apariencia intrascendentes de don Pedro no encajaban en esa imagen de Calderón como autor grave, de ahí que se fuesen relegando progresivamente hasta llegar a la situación actual, en la que de las decenas de comedias del Calderón cómico, solo La dama duende encuentra frecuente acomodo sobre las tablas y en las colecciones de clásicos más difundidas, mientras que las demás apenas son representadas y deben ser

\footnotetext{
${ }^{15}$ Citado en Pérez-Magallón, 2010, p. 118. La cursiva es mía.

16 Remito para más detalles y abundante bibliografía al citado libro de PérezMagallón, 2010.

${ }^{17}$ Como explica Sergio Adillo, «un repertorio calderoniano tan amplio y poliédrico como el que se exhibía en las carteleras del primer siglo XviII difícilmente podía funcionar como elemento identitario, y de ahí que la praxis teatral fuese decantando poco a poco un canon escénico mucho más limitado y cerrado, que sería el que llegase al centenario de 1881» (tesis doctoral en curso, cap. I).
} 
leídas en ediciones críticas manejadas por especialistas o bien en colecciones de obras completas (cabe añadir también entre paréntesis que las adaptaciones cinematográficas de estas obras son prácticamente nulas, en particular si pensamos en películas que hayan tenido un mínimo de éxito o repercusión, aunque este es un problema que afecta a todo el teatro clásico español, en contraste evidente con lo que sucede en el británico con las piezas de Shakespeare).

Probablemente el episodio más extremo de este proceso de conversión de Calderón en un autor exclusivamente serio fue el constituido por diferentes artículos que dieron lugar a las llamadas lecturas tragedizantes de comedias cómicas. Se trata de trabajos de autores mayoritariamente del ámbito anglosajón, como Bruce Wardropper, Adrienne Schizzano o Barbara Mujica, entre otros, que leían comedias cómicas de Calderón, en particular La dama duende, como si de una tragedia se tratase, como el envés o la premonición de El médico de su honra. Estos artículos partían de negar en la práctica la capacidad de Calderón para hacer comedia, ya que se trataría de un autor eminentemente serio, o trágico, con una visión del mundo coherente y unívoca que se desplegaría por igual en toda su obra, al margen del género de que se tratase.

Es sabido que el prestigio de los géneros trágicos y serios ha sido y sigue siendo mayor que el de los propiamente cómicos. De ahí que varias de estas lecturas tragedizantes parezcan nacer del objetivo, en apariencia loable, de dotar de un mayor prestigio a este tipo de obras ${ }^{18}$. Quizá por esta razón, la fortuna crítica de estas aproximaciones fue notable, y predominaron durante años entre los muchos críticos, no solo norteamericanos, que se acercaron a La dama duende y otras obras cómicas. Solo hacia finales de siglo aparecieron diferentes trabajos en los que se discutían convenientemente estas lecturas y se reivindicaba la necesidad de releer estas comedias en su clave cómica, de acuerdo con el género en el que se insertan y con el horizonte de expectativas para el que fueron creadas ${ }^{19}$.

Sin embargo, me pregunto en qué medida estas relecturas cómicas han revocado la perspectiva tragedizante, pues parece mantenerse con cierto éxito esa imagen de Calderón como autor serio, en tanto que sus obras cómicas siguen siendo vistas como excusa para interpretaciones

18 Antonucci, 1999, p. XLVII.

${ }^{19}$ Ver, por ejemplo,Vitse, 1990, pp. 306-341; Iglesias Feijoo, 1998; Arellano, 1999. 
serias, al tiempo que los trabajos que analizan la comicidad de Calderón como tal siguen siendo escasos.

Así, y a manera de ejemplo, Christoph Strosetzki, en su valioso libro de introducción a Calderón, publicado en 2001, divide el teatro de este en seis capítulos que se corresponden con diferentes géneros (dramas religiosos, dramas mitológicos...), y en uno de ellos analiza significativamente juntas las tragedias de honor (Ehrentragödien) y las comedias cómicas (Verwechslungskomödien) ${ }^{20}$. De igual modo, la comedia cómica a la que presta más atención es La dama duende, aunque la mayor parte del espacio en que la trata está dedicada a glosar las lecturas serias de ter Horst, Neuschäfer y, particularmente, Mujica ${ }^{21}$. Pero debe añadirse que Strosetzki no llega a equiparar ambos géneros, a pesar de las dificultades que encuentra para delimitarlos ${ }^{22}$.

Esta tensión entre el Calderón serio y el cómico se aprecia también en la reciente edición de La dama duende publicada en 2011 por Jesús Pérez Magallón, quien, aunque señale que el primer objetivo de la comedia consiste en entretener y divertir al público, no cerrará las puertas a opiniones más trascendentes. Esta voluntad de reivindicar un cierto sentido serio de La dama duende, no reñido con su primaria finalidad cómica, pero sin caer en excesos tragedizantes, será un objetivo primario de su edición y permeará la introducción y la extensa anotación en un dificil equilibrio que puede llegar a resultar ambiguo, pues se da cabida en ocasiones a algunas interpretaciones que solo muy forzadamente se ajustan a los versos que comentan ${ }^{23}$.

Aunque La dama duende ha sido la comedia calderoniana sobre la que más interpretaciones serias de todo tipo se han escrito, la tentación de lo serio también ha nacido a partir de comedias menos conocidas, como sucede con El astrólogo fingido. Es esta acaso la más temprana de las comedias de capa y espada de Calderón, escrita probablemente en 1625 y publicada en $1632^{24}$. En ella se solapan dos tramas: la primera, de ámbito amoroso, se plantea en la primera jornada y se desarrolla alrededor de dos triángulos. El principal tiene como vértice a María, a la que pretenden don Diego, noble y rico pero rechazado por María, y don Juan,

\footnotetext{
${ }^{20}$ Strosetzki, 2001, pp. 47-77.

${ }^{21}$ Strosetzki, 2001, pp. 75-77.

${ }^{22}$ Strosetzki, 2001, p. 47.

${ }^{23}$ Para más detalles puede verse Rodríguez-Gallego, 2013.

${ }^{24}$ Ver Calderón de la Barca, El astrólogo fingido, pp. 11-12.
} 
pobre pero que será correspondido. Don Juan, a su vez, es el vértice del triángulo secundario, del que también forman parteViolante, enamorada de Juan, y Carlos, amigo de Juan pero enamorado de Violante.

Pero esta trama amorosa, planteada en la primera jornada, queda temporalmente interrumpida en la segunda debido a una nueva trama que se impone sobre ella. Don Diego tiene sobornada a la criada de María, Beatriz, para que lo informe de cuanto pasa en su casa y lo ayude en sus pretensiones amorosas. A través de ella y de su propio criado, Morón, don Diego descubre los amores de María y don Juan y no puede evitar reprochárselo abiertamente a María al inicio de la segunda jornada, con lo que Beatriz queda en evidencia. Morón, para protegerla, se inventa que don Diego es astrólogo y ha descubierto los amores de María y Juan a través de su astrología; don Diego sustenta la mentira a través de una autobiografía ficticia y la fama de su astrología se expande en muy poco tiempo. Así, en las jornadas segunda y tercera distintos personajes van a consultarle, y don Diego siempre encuentra la respuesta adecuada gracias a informaciones que le llegan oportunamente, lo que genera diferentes equívocos que se entremezclan con los amorosos hasta llegar al feliz desenlace.

Esta ingeniosa y divertida trama ha dado también pie a algunas interpretaciones serias que, aunque no tan hiperbólicas como las tragedizantes, sí entiendo que pecan de no respetar la fundamental distinción genérica, así como de no tener en cuenta el contexto del que extraen los pasajes que les sirven para sus interpretaciones. Asimismo, parten de determinadas bases, como en qué consista la cultura barroca, por ejemplo, y ello se quiere aplicar de una manera forzada a los lances argumentales de la comedia.

Así sucede en un artículo de Max Oppenheimer de 1948 sobre la burla en El astrólogo fingido. El autor analiza los diferentes elementos que componen la comedia en un esfuerzo por demostrar que todos ellos responden a un mismo patrón de pensamiento, que se correspondería con la mentalidad barroca. De este modo, a partir de la abundancia de burlas y engaños presentes en la comedia, concluye que en toda la obra hay una continua preocupación de los personajes por si lo que les ocurre es real o solo lo aparenta, de tal manera que la comedia estaría llena de seres atormentados por las dudas, lo que los conduce a acudir a un astrólogo. Oppenheimer percibe en la obra la presencia constante del sentimiento de inseguridad, del problema de determinar la verdad obje- 
tiva, de la convicción de que no se puede estar seguro de prácticamente nada, y concluye:

we might say that the burla is an illustration of the tema de la realidad oscilante, that it is one of the elements of casuistical logic and reasoning and partly symbolizes man's struggle to extricate himself from the paradoxes which constantly arise because of the clash between theory and practice, because of the artificial laws set up by man to fix, limit, and petrify elements whose very plasticity forever evades inflexible imprisonment. The burla is man's realization of his inability to fathom the mysteries of nature, and the frustrating awareness of human impotence ${ }^{25}$.

Nada menos, cabría añadir. Quien lea el artículo de Oppenheimer sin conocer la pieza de Calderón concluirá que esta es una suerte de drama filosófico, en absoluto cómica. Aunque en la primera página de su trabajo sí se refiere a la obra como "comedia de capa y espada", de inmediato olvida este aspecto y no atiende en absoluto al lado cómico del texto, a sus equívocos, al enredo y a la risa, pues siempre se percibe la burla desde una perspectiva que podríamos denominar filosófica o existencial.

El artículo de Oppenheimer es valioso y desarrolla varias ideas interesantes, y probablemente parta de una sincera admiración hacia la obra que le lleva a querer afirmar la importancia de esta buscándole un sentido filosófico. Pero entiendo que la desnaturaliza al privarla de su objetivo inicial, que es la creación de una trama ingeniosa y lúdica, el enredo que lleva a magistrales escenas llenas de equívocos, que no generan en el espectador la angustia de no saber si lo que ve es real o mentira, sino la risa. Pareciera que, al tratarse de un texto dramático situado en el período barroco, hubiera de reflejar forzosamente las supuestas características de este tiempo, entendido además de manera unívoca, sin importar otros detalles y características de la pieza.

También cabe reconocer a Oppenheimer su condición de pionero, pues en una fecha tan temprana como 1948 adelanta ideas que se volverían habituales a partir de las lecturas serias y tragedizantes que Wardropper puso de moda quince años después. Sin embargo, y quizá por haber tratado una obra no tan importante como La dama duende, su artículo apenas se ha discutido; al contrario, Frederick A. de Armas lo

${ }^{25}$ Oppenheimer, 1948, p. 254. 
considera ya clásico ${ }^{26}$ y ha sido citado de manera quizá demasiado acríti$\mathrm{ca}$, me parece, por otros autores. Así sucede en un artículo de alguien tan poco sospechoso de pecar con lecturas tragedizantes como Carlos Mata Induráin, quien analiza en detalle el episodio de la burla al escudero vejete Otáñez del Astrólogo junto con la fuente a la que se homenajea, el fingido vuelo de don Quijote y Sancho sobre Clavileño en el Quijote (II, 40-41). A Mata le interesa especialmente la función de burla que desempeñan ambos pasajes en el contexto de sus respectivas obras, lo que lo lleva a servirse del artículo de Oppenheimer.Y, basándose en él, cierra su artículo con la conclusión de que en este episodio común

Los dos autores [Cervantes y Calderón] supieron plasmar genialmente en sus respectivas creaciones el gran problema barroco - $\mathrm{y}$ universal- del choque entre el mundo de la realidad y el de la ficción, la verdad y la mentira, lo que es y lo que parece ser (lo que Oppenheimer llamó «el tema de la realidad oscilante» $)^{27}$.

Sin embargo, entiendo que este episodio más bien debe ser visto dentro del contexto de las peticiones absurdas que se le realizan a don Diego debido a su supuesta astrología ${ }^{28}$. En efecto, el escudero Otáñez le pide que lo lleve a la Montaña santanderina por arte de magia para ahorrarle las penurias del camino. Don Diego delega el cumplimiento de la petición en su criado Morón, quien quiere burlar al simple Otáñez y le hace montar sobre un banco de madera, lo ata y le tapa los ojos, en recuerdo del episodio de Clavileño. El pasaje es netamente jocoso, y puede ser visto como una suerte de entremés empotrado ${ }^{29}$ dentro de la trama de la comedia.

Una similar búsqueda forzada de contenido serio dentro del Astrólogo se aprecia en un artículo de Adrienne Schizzano de 1991. Schizzano se

${ }^{26}$ De Armas, en prensa.

${ }^{27}$ Mata Induráin, 2001, p. 1011.

${ }^{28}$ Así, de manera más ajustada entiende Arellano que la escena «está perfectamente pensada como culminación jocosa de una trama de credulidades ridículas objeto de sátira, concebida en modo especular al trasladar a los dos personajes subalternos, en clave más ridícula aún, la relación establecida entre los otros peticionarios y el astrólogo fingido" (Arellano, 2006, p. 134).

${ }^{29}$ Fernández Mosquera, 2015b. También De Armas se refiere al episodio como "entremés intercalado», y afirma: «El fin de la comedia es de risa pues el entremés de Otáñez se integra a la conclusión en la cual brota la alegría ya que don Juan casará con María» (en prensa). 
centra en uno de los lances más brillantes de la pieza: la autobiografia ficticia que, al inicio de la segunda jornada, crea don Diego sobre la marcha para sustentar la mentira en torno a su astrología que lanza el gracioso Morón para proteger a Beatriz de la ira de su ama, pues solo Beatriz podría haber contado a don Diego los amores de doña María con su pretendiente Juan. Don Diego pide a Morón una «industria» para salir de tan apretada situación (versión de QC, vv. 986-993), y Morón construye una según la cual don Diego es un astrólogo que aprendió su ciencia en Italia con un maestro (vv. 1010-1011). Gracias a sus conocimientos, entre astrológicos y mágicos, don Diego pudo ver las visitas nocturnas de don Juan a María en un espejo (vv. 1026-1035).

«Esto es verdad» (v. 1035), concluye Morón, pero es todo mentira y, para sustentarla, don Diego inicia un largo romance de más de cien versos (versión de QC, vv. 1039-1158) en el que finge una trayectoria biográfica que lo habría llevado hasta Nápoles (v. 1063). Allí habría conocido a Giambattista della Porta (v. 1065), quien lo habría iniciado en los misterios de la astrología, e incluso de la magia. Por ello, y debido a unos supuestos problemas con la Inquisición (que fueron reales en el caso de Della Porta), don Diego habría ocultado sus conocimientos astrológicos desde entonces (vv. 1120-1125), hasta que decidió volver a recurrir a ellos para descubrir por sí mismo cuál fuese la causa de los desprecios de María (vv. 1127-1141) ${ }^{30}$.

El relato de don Diego constituye una burla magnífica que deja admirado incluso a su criado, quien le dice:

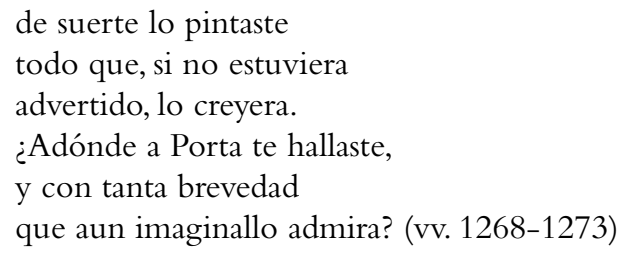

A lo que don Diego contesta:

${ }^{30}$ Este fingir ser algo que no se es no resulta algo excepcional del personaje de don Diego. Recuérdense, entre otros muchos ejemplos, el fingido maestro de danzar creado por Calderón en El maestro de danzar, o el fingido profesor de latín en que se convierte Felipe en Marta la piadosa, de Tirso. 


\section{Morón, la buena mentira \\ está en parecer verdad (vv. 1274-1275)}

Esta mención de Della Porta, ese hombre «curiosamente docto», en palabras de Quevedo ${ }^{31}$, es por supuesto interesantísima, pues cabe preguntarse por el interés que haya podido tener Calderón hacia él, qué textos suyos podría haber leído, etc. Por ello mismo Frederick de Armas ha dedicado un capítulo a la cuestión en su libro sobre la astrología en el teatro clásico europeo ${ }^{32}$.Y de ahí también el germen del estudio de Schizzano, que atiende además a los cambios que se introdujeron en diferentes versiones que se hicieron del Astrólogo a lo largo del XVII en lo que respecta a la figura de este astrólogo supuesto maestro de don Diego. Schizzano comienza señalando que «la astrología sirve aquí de pretexto a la construcción de un universo lúdico» ${ }^{33}$, premisa correcta, en mi opinión, pero que, sin embargo, será olvidada de inmediato. Así, la autora entiende que esa fingida autobiografia que se inventa don Diego esconde otra, una vivencia más auténtica, de tal manera que el perseguido Della Porta serviría de pre-texto con el que Calderón mostraría sus preocupaciones por el problema de la censura, así como un enfrentamiento con su público ${ }^{34}$, aunque no justifica Schizzano en dónde lo encuentra ni qué en concreto la lleva a pensar así. Más adelante, concluye:

La lectura del texto calderoniano ofrece dos posibles niveles de significación. Por un lado, se presenta la imagen burlesca del uso que se hace de la astrología, flá]cilmente asociado con el engaño y el disfraz; por otro, se revela como un intento de reivindicar la auténtica investigación y el conocimiento científico. A nuestro parecer, la perspectiva del autor dentro del marco extra-literario consiste en justificar el derecho a la actividad intelectual, al conocimiento y a la investigación científica. [...] consideramos que en el parlamento de don Diego está expuesta y encubierta la defensa de la astrología ${ }^{35}$.

Reconozco que me resulta imposible encontrar en el texto de Calderón estos elementos que señala Schizzano, por varias razones. En

${ }^{31}$ Quevedo, Providencia de Dios, p. 170.

32 De Armas, en prensa. Agradezco al profesor De Armas el haberme enviado el capítulo correspondiente al Astrólogo antes de la publicación del libro.

33 Schizzano, 1991, p. 162.

${ }^{34}$ Schizzano, 1991, p. 165.

${ }^{35}$ Schizzano, 1991, p. 170. 
primer lugar, esa supuesta defensa de la astrología, que está lejos - entiendo - de ser el objetivo del parlamento de don Diego, y menos aún de toda la comedia, pues en ella la astrología, y la credulidad en torno a ella, son satirizadas de manera constante. De igual modo, esa supuesta defensa de la auténtica investigación o del conocimiento científico supone forzar al texto a decir lo que no dice, en particular en el contexto en el que lo dice.Y además, Schizzano no acude a otras fuentes o argumentos para justificar su postura, sino tan solo a la interpretación que hace del texto, que entiendo que es muy forzada y descontextualizada. De nuevo parece que el problema fundamental consiste en querer buscar lecturas serias, profundas, a toda costa, con el posible y loable objetivo de reivindicar la valía del texto calderoniano, aunque errando el camino por desnaturalizar la pieza: el mérito del Astrólogo estaría en su carácter serio; de nuevo sería la seriedad última la que daría validez a la obra.

Debe alabarse la agudeza de Schizzano al fijar su atención en un pasaje tan rico, en particular en la mención de Della Porta, personaje muy estimulante. Por tal razón ha sido reivindicado su artículo recientemente en el mencionado capítulo de Frederick de Armas sobre El astrólogo fingido. Pero entiendo que este mismo trabajo pone de relieve los defectos del artículo de Schizzano, ya que el estudioso norteamericano parte de una perfecta contextualización del pasaje y se pregunta precisamente por el conocimiento que tiene de Della Porta un personaje que en otros pasajes de la comedia insiste en no saber de astrología, tensión cómica presente en diferentes lugares de la obra, como cuando don Diego se reafirma ante el anciano Leonardo en su desconocimiento de la astrología (vv. 2356 y ss.). Ello lleva también a De Armas a preguntarse por el interés que pudiera haber tenido Calderón hacia la obra de Della Porta, buscando reflejos de esta en los textos de aquel. Pero De Armas no pierde de vista la dimensión cómica y de enredo de este pasaje dentro de la comedia.

No quería ser el principal propósito de este artículo criticar sin más diferentes trabajos de otros autores, pero acudir a ellos me parecía la mejor manera de ejemplificar esta tentación de lo serio que ha ido más allá de la lectura tragedizante de La dama duende y alguna otra obra. Obviamente, las comedias cómicas de Calderón abren la puerta a estudios de toda índole y desde diferentes perspectivas, pero en ocasiones se ha olvidado que los elementos que las componen estaban puestos al ser- 
vicio de complejas arquitecturas dramáticas que buscaban la admiración y la risa del público ${ }^{36}$. Debido probablemente a la minusvaloración de lo cómico frente a lo dramático o lo trágico, se ha buscado el lado serio del Calderón cómico con la probable buena intención de reivindicar esa parte del teatro de don Pedro de apariencia más liviana y frívola dándole una pátina de seriedad, y así construir una más coherente imagen del autor como escritor grave y profundo. Sin embargo, frente a esa tentación de lo serio, entiendo que es importante reivindicar la vertiente lúdica, cómica y acaso hasta sanamente superficial de Calderón, lo que nos permite componer una imagen más compleja del escritor, que no era, o no era únicamente, ese autor serio, grave y ceñudo solo amigo de tragedias sangrientas, dramas filosóficos y autos sacramentales, sino también uno de los más hábiles constructores de universos lúdicos y de ingeniosos enredos que ha dado la literatura universal.

${ }^{36} \mathrm{Y}$ así sigue siendo cuando estas obras llegan a las tablas, como sucede, en el caso de El astrólogo fingido, con los montajes de José Luis Sáiz de 1991, el de Gabriel Garbizu de 2004 o el de Zhenghog y González Puche de 2002 (ver Calderón de la Barca, El astrólogo fingido, p. 17). Las lecturas tragedizantes no llegan a la escena; se quedan en el mundo académico, como quizá no pueda ser de otra forma. 


\section{BibLIOGRAFÍA}

Adillo Rufo, Sergio, «Calderón en el siglo xxi: ¿un nuevo modelo de producción para el teatro clásico?», comunicación presentada en el Congreso Internacional Teatro século XXI,Vigo, 27-29 de noviembre, 2013.

Adillo Rufo, Sergio, Calderón en los teatros españoles (1715-2015), tesis doctoral en curso, Universidad Complutense de Madrid.

Antonucci, Fausta, «Prólogo» a Pedro Calderón de la Barca, La dama duende, ed. Fausta Antonucci, estudio preliminar Marc Vitse, Barcelona, Crítica, 1999, pp. XXIX-LXXIII.

Arellano, Ignacio, «Metodología y recepción: lecturas trágicas de comedias cómicas», en Convención y recepción: estudios sobre el teatro del Siglo de Oro, Madrid, Gredos, 1999, pp. 13-36 (antes en Criticón, 50, 1990, pp. 7-21).

Arellano, Ignacio, «Cervantes en Calderón», en El escenario cósmico. Estudios sobre la comedia de Calderón, Madrid / Frankfurt, Iberoamericana / Vervuert, 2006, pp. 123-52 (versión original publicada en Anales cervantinos, 35, 1999, pp. 9-35).

Bances Candamo, Francisco, Theatro de los theatros de los passados y presentes siglos, ed. Duncan W. Moir, London, Tamesis, 1970.

Calderón de la BArCa, Pedro, El astrólogo fingido, ed. Fernando RodríguezGallego, Madrid / Frankfurt, Iberoamericana / Vervuert, 2011.

Calderón de la Barca, Pedro, Comedias, V.Verdadera quinta parte de comedias, ed. José M. ${ }^{a}$ Ruano de la Haza, Madrid, Biblioteca Castro, 2010.

Calderón de la Barca, Pedro, La desdicha de la voz, ed.T. R. A. Mason, Liverpool, Liverpool University Press, 2003.

De Armas, Frederick, «Claves políticas en las comedias de Calderón: el caso de El mayor encanto amor», Anuario Calderoniano, 4, 2011, pp. 117-144.

De Armas, Frederick, «Una constelación de astrólogos: Della Porta, Himbert de Billy, Nostradamus y William Lilly», en La astrología en el teatro clásico europeo: de Lope de Vega a Shakespeare, Madrid,Verbum, en prensa.

Fernández Mosquera, Santiago, «El significado de las primeras fiestas cortesanas de Calderón de la Barca», en Calderón: texto, reescritura, significado $y$ representación, Madrid / Frankfurt, Iberoamericana / Vervuert, 2015a, pp. 199-240.

Fernández Mosquera, Santiago, «Entremeses empotrados en comedias: un ejemplo en La señora y la criada», en Calderón: texto, reescritura, significado y representación, Madrid / Frankfurt, Iberoamericana / Vervuert, 2015b, pp. 170-183.

Ferrer Valls, Teresa (dir.), Diccionario biográfico de actores del teatro clásico español (DICAT). Edición digital, Kassel, Reichenberger, 2008. 
Ferrer Valls, Teresa et alii, Base de datos de comedias mencionadas en la documentación teatral (1540-1700). CATCOM, publicación en web: <http://catcom. uv.es> [01/10/2016].

IgLesias Feijoo, Luis, «"Que hay mujeres tramoyeras”: la "matemática perfecta” de la comedia calderoniana”, en La comedia de enredo. Actas de las XX Jornadas de teatro clásico, Almagro, julio de 1997, ed. Felipe B. Pedraza Jiménez y Rafael González Cañal, Almagro, Universidad de Castilla-La Mancha / Festival de Almagro, 1998, pp. 201-236.

Mascarell, Purificació, «El canon escénico del teatro clásico español: del siglo XVII al XX», Teatro de palabras, 7, 2013, pp. 305-317. Disponible en línea: $<$ http://www.uqtr.ca/teatro/teapal/TeaPalNum07Rep/17MascarellPurifi cacio.pdf $>$ [01/10/2016].

Mascarell, Purificació, El Siglo de Oro español en la escena pública contemporánea: la Compañía Nacional de Teatro Clásico (1986-2011), tesis doctoral dirigida por Teresa Ferrer Valls, Universitat de València, 2014.

Mata Induráin, Carlos, "Cervantes y Calderón: el episodio de Clavileño (Quijote, II, 40-41) y la burla a Otáñez en El astrólogo fingido», en Volver a Cervantes. Actas del IV Congreso Internacional de la Asociación de Cervantistas, ed. Antonio Bernat Vistarini, Palma, Universitat de les Illes Balears, 2001, t. II, pp. 999-1014.

MÉrimée, Paul, L'art dramatique espagnol dans la première moitié du dix-huitième siècle: extraits essentiels de la thèse soutenue en 1955, Toulouse, Faculté de Lettres, 1975.

Oppenheimer, Max jr., "The burla in Calderón's El astrólogo fingido», Philological Quarterly, 27, 3, 1948, pp. 241-263.

Pérez-Magallón, Jesús, Calderón. Icono cultural e identitario del conservadurismo político, Madrid, Cátedra, 2010.

Pérez-Magallón, Jesús (ed.), Pedro Calderón de la Barca, La dama duende, Madrid, Cátedra, 2011.

Quevedo, Francisco de, Providencia de Dios, ed. Sagrario López Poza, A Coruña, SIELAE, 2015.

Rodríguez-Gallego, Fernando, "Calderón ríe. A propósito de una nueva edición de La dama duende», Criticón, 117, 2013, pp. 109-117.

Schizzano Mandel, Adrienne, «Della Porta: El astrólogo non fingido de Calderón», en Hacia Calderón. Noveno coloquio anglogermano, ed. Hans Flasche, Stuttgart, Franz SteinerVerlag, 1991, pp. 161-180.

Strosetzki, Christoph, Calderón, Weimar / Stuttgart, Verlag J. B. Metzler, 2001. Vega García-Luengos, Germán, «El teatro barroco en los escenarios y en las prensas de Valladolid durante el siglo XviII", en Teatro del Siglo de Oro: homenaje a Alberto Navarro González, Kassel, Reichenberger, 1990, pp. 639-673.

VITSE, Marc, Éléments pour une théorie du théâtre espagnol du XVII siècle, Toulouse, Presses Universitaires du Mirail, 1990. 